\title{
A NOTE ON SOME ISSUES RAISED FOR SCIENCE AND TECHNOLOGY POLICY BY THE INCREASE IN OIL PRICES
}

\section{Ray Curnow*}

The intention of this note is to explore some of the issues to the role of science and technology in effecting changes in the patterns of demand and supply of raw materials. Although the paper is chiefly concerned with the current technological response to the oil crisis, it is clear that in examining the international market for raw materials we are concerned with a phenomenon with two main components the first being the distribution of consumption and production of raw materials between nation states, and the second being the distribution of science and technology. In one sense, the concept of "parity" between the price of raw materials and the price of manufactures is valid only to the extent that the otherwise independently determined two price levels are related at source by the outcome of the science and technology system; an outcome determined by the evolution of science and technology which largely takes place in Western consuming countries.

The world market for a given commodity involves a number of major participants: national governments, particularly in the case of developing countries; private firms in the case of developed market economies; and (increasingly) multinational companies which carry out transfers both ways. Attempts at commodity agreements in the past have sometimes tended to omit one or other of the key participants (particularly multinational companies) a factor which has been a major defect in the operation. It is a central contention of this paper that a still greater defect is that such agreements have often ignored the role of Science and Technology in determining the range of materials which at any given moment are regarded as resources, and the continual redefinition of that range (and therefore of dependence on particular raw materials) according to the direction of science and technology. This, in turn, is influenced strongly by those who determine science and technology policy, whether they be in the government or private sector.

* Ray Curnow is a Senior Research Fellow in the Science Policy Research Unit, University of Sussex. 
A NOTE ON SOME ISSUES RAISED FOR SGIENCE AND TECHNOLOGY POLICY BY THE INCREASE IN OIL PRICES

It might be argued that, except in the special case of oil, this process of resource redefinition has not been stimulated by recent events. However, given that many raw material sectors, and particularly mineral extraction and refining, are highly energy-intensive, it seems certain that the need to adjust resource usage patterns will be under serious consideration due to imbalances in those patterns brought about by the discontinuous shift in their cost characteristics. Even if no OPEC-type actions occur in other commodities, substantial shifts in demand and supply patterns for most raw materials will occur as a consequence of OPEC action on oil.

\section{Consumer Options ${ }^{1}$}

Using the working assumption that a quite significant technological response to the current situation will occur, the strategies open to consumer nations will tend to stress heavily a decrease in dependence on imported supplies.

As the previous two articles have brought out there are various steps which are possible for achieving this - increasing supply (exploration in new countries, seabed, Antarctica, etc; faster and cheaper development of existing sources) or reducing consumption (more efficient designs; using prices and social pressures: re-use or re-cycling; substitution with different materials).

In addition, a strategy of this kind can be supported by research in key areas. A fuller understanding can be developed of the criticality and essentiality of some materials (not necessarily just those which are bulky or expensive) - e.g. materials used in telecommunications, computing, aircraft, etc., and metal "vitamins" in particular. The cost, time and momentum of possible technical changes and their institutional implications can be studied.

Much of the basic information required for evaluating or implementing these strategies does not exist in an accessible form at the present time. This is largely because there is no systematic framework for the central collection and collation of the

\footnotetext{
1 This discussion on strategies and options is heavily indebted to Page, W., “Mineral Dependences and Technological Moves” (Resource Policy, Sept. 1974).
} 
A NOTE ON SOME ISSUES RAISED FOR SCIENCE AND TECHNOLOGY POLICY BY THE INCREASE IN OIL PRICES

technological knowledge possessed by countless different firms and research centres. Undoubtedly, studies on material flows, possibilities of substitution, re-use and recycling, and supporting $\mathrm{R} \& \mathrm{D}$, are currently being carried out on a large scale by many independent researchers; but only to the extent that this is readily available to policy makers would it be possible to undertake the kind of informed studies which would enable consumer countries to quantify the feasibility and cost of a given reduction in dependence on particular imported raw materials.

Despite the overwhelming concentration of world research and development capability in the major consuming countries, it is not distributed evenly (just as the burdens of the oil price increase are also unevenly distributed). It is pertinent that US dependence on imported oil, whilst massive in absolute amount, is still low relative to that of Western Europe, let alone Japan. The responsiveness of the research and development structures in these three zones is not easy to analyse, however; the Western European response capability would appear lower than that of USA and Japan. This ignores the possibility of transferring raw materials or energy-saving technology between these three blocs, but some writers have suggested that the USA would not be loath to see a weakening of the competitive power of Japan and Western Europe, and will sell dearly any relevant technology she develops.

\section{Producer Options}

For many commodities, particularly minerals, a high proportion of production occurs inside the consumer countries themselves. The attitudes of these consumer-producers towards, for example, higher prices or disruption in imports is clearly a mixed one and will involve inter alia their degree of diversification, the market income they wish to protect, the embodied technology they wish to protect, and the roles they can play in technological response. The position of developing country primary commodity suppliers is more straightforward. Whilst it is difficult to generalise due to the wide variation in circumstances affecting each commodity, and the varying interests of individual countries in single commodities or mixes of commodities, the following may present some of the major strategies open to countries which are primarily producers: 
A NOTE ON SOME ISSUES RAISED FOR SCIENCE AND TECHNOLOGY POLICY BY THE INCREASE IN OIL PRICES

(i) consider the possibilities of cartelisation, but only after evaluating all the consumer options for response, timescale and momentum;

(ii) understand the role of the exports in the consumer economy and follow the development of the consumer's technological response closely;

(iii) intensify exploration for new deposits of materials currently used as resources;

(iv) intensify development of lower extraction cost processes for these materials;

(v) seek new uses for these materials with higher local added value;

(vi) look out for sources of raw materials capable of becoming resources;

(vii) direct research and development to the uses of local materials.

Given the disparity in the distribution of research and development effort between most primary producing countries and the major consumer countries, the actual technological options open to such producer countries are not very convincing. Nevertheless, desk research and the better use of the technical information services so widely available in the market economies of the consumer countries are cheap; and are now priorities in the preparation of strategies. Where exploration is concerned, a better understanding of the potential breakthrough implied by satellite technology and greater use of available NASA data would also appear a priority. It is particularly relevant that location of likely oil or mineral bearing geological strata is accelerated by satellite capability.

\section{Multinational Companies}

Clearly the multinational companies engaged in exploration and trade form a major group of interests in the unfolding strategies and responses in commodity markets. Here again it is difficult to 
A NOTE ON SOME ISSUES RAISED FOR SCIENCE AND TECHNOLOGY POLICY BY THE INCREASE IN OIL PRICES

generalise about even the sub-group of multinational companies handling raw materials. Amongst the factors which will help determine their posture are the following:

(i) level of their technology;

(ii) location of investment and technology to be protected;

(iii) ability to switch to other raw materials taking account of technological constraints;

(iv) ability of their own research and development centres to new situations.

\section{Some General Science and Technology Considerations}

There is a danger that a sudden and sharp acceleration of the technological response may result in losses to all the participants in raw materials trade. This is because the costs of such technological response are considerable and might well exceed or overstress the availability of skills, engineering and capital. Further, any ill-planned over-expansion of technical change in a particular direction opens up the possibility of overshooting the desired substitution of a particular raw material, with the consequence of an eventual slump in the substituting industry while the requirement for adjustment weakens, together with the waste normally associated with boom-slump sequences.

There is evidently a trade off for consuming countries between the costs of sharp discontinuities in the price or supply (including the cost of sudden accelerations in technological response) on the one hand, and the price they would be prepared to pay for guaranteed continuity on the other. Similarly, for exporting countries there is a trade off between the desire for higher prices and the risk that the technological response in consumer countries will greatly diminish the demand for their commodity. Clearly a joint maximising solution should be feasible between these sets of trade offs, and it becomes an important question for science and technology policy-makers in consumer countries whether the technological processes of 
substitution and resource saving should be slowed down or given a different pattern of emphasis in return for stability.

The central issue on which science and technology policy analysts in consumer countries should be working at the moment is to establish whether the trade off based on the need for stability indeed exists in any quantifiable form. Such work would seek to find answers to such questions as what are the true costs of disruption in supply or price, and of an "overstimulated" response. These are complex, difficult questions and any attempts at forecasting other than on a scenario basis are clearly ruled out, at least until much more information becomes available. Nevertheless, analysis, exposure, and debate of the issues involved are clearly vital, if the world economic order is not to run the risk of disruption which in the short run would be costly and in the long run, potentially calamitous. 